\title{
LM23 is a novel member of the Speedy/Ringo family at the crossroads of life and death of spermatogenic cell
}

\author{
Yi-Ming Cheng ${ }^{1,2,3}$, Mei-Ling Liu $^{2}$ and Meng-Chun Jia ${ }^{2}$
}

LM23 is a gene specifically expressed in the testis of Rattus norvegicus, as previously reported by our laboratory. The aim of the study is to further investigate the biological function of LM23. Several bioinformatic tools were utilized, including PROSITE and BLAST. To determine the subcellullar localization of LM23, a polyclonal antibody specific for LM23 was generated via the immunization of rabbits. The $L M 23$ gene was cloned from rat testis tissue, and LM23 protein was expressed in Escherichia coli. The biological function of LM23 was analyzed with microarray analysis and immunohistochemistry, using a rat model of $L M 23$ gene knockdown. The results suggested that LM23 belongs to the Speedy/Ringo family. $L M 23$ regulated the $G_{1} / S$ and $G_{2} / M$ transitions of the cell cycle during spermatogenesis. Downregulation of the $L M 23$ gene during spermatogenesis could lead to the activation of both the Fas-Fas $L$ pathway and the mitochondrial pathway. These novel findings indicate that LM23 has a diverse array of functions that are important in both the life and death of the spermatogenic cell.

Asian Journal of Andrology (2011) 13, 446-452; doi:10.1038/aja.2011.21

Keywords: cell cycle; LM23; spermatogenesis; spermatogenic cell

\section{INTRODUCTION}

Spermatogenesis is the process of differentiation of male germ cells into mature spermatozoa. It is divided into three distinct stages: the mitotic proliferation of spermatogonial stem cells, the meiotic division of spermatocytes and the maturation spermiogenesis of haploid spermatids. ${ }^{1}$ These processes are subject to transcriptional, translational and post-translational regulation. The genes expressed during these processes encode proteins that are specific to the different phases of germ cell development. With the development and application of technologies such as gene cloning, gene expression and functional characterization, many spermatogenesis-related genes have been identified in the past few years. Some of these genes have been proven to play important roles in spermatogenesis.

$L M 23$, a gene expressed specifically in the testis in a stage-specific manner, was previously identified by our laboratory. ${ }^{2}$ The sequence of LM23 was submitted to GenBank and the accession number is AF492385. Northern blot and RT-PCR analysis showed that LM23 was specifically expressed in testis, and its expression was not detected in other tissues. Real-time PCR analysis showed that the expression level of LM23 was the highest in spermatocytes and the lowest in spermatogonia. In situ hybridization revealed a strong positive signal in spermatocytes. These results indicate that LM23 possesses testisspecific and stage-specific expression characteristics and is involved in rat spermatogenesis. To reveal the function of $L M 23$ in the testis, lentivirus-mediated RNA interference was used to knock down LM23 expression in a tissue-specific manner in vivo. A lentiviral vector expressing a short hairpin RNA (shRNA)-targeting LM23 was microinjected into the efferent ducts of Rattus norvegicus testis. The expression of $L M 23$ in the treated testis was markedly knocked down compared to controls. The LM23-shRNA testis contained germ cells that were arrested at the spermatocyte stage, and showed increased apoptosis and dysregulation of some meiotic genes. ${ }^{3}$

In this study, we presented novel functional and structural features of LM23, as predicted by bioinformatic analytical tools. The integrated bioinformatics database PROSITE and BLAST tools were used to analyse LM23. A BLAST homology search using against the NCBI nonredundant database and an Ambystoma EST database reveal that LM23 is an R. norvegicus homolog of Speedy A (Spdya, Spy, also called Ringo). Speedy was initially identified in Xenopus as a protein, which induced the $\mathrm{G}_{2} / \mathrm{M}$ transition during oocyte maturation by activating Cdk1 and Cdk2. No data regarding the role of Speedy in spermatogenesis have been published until now. Cheng et al. ${ }^{4}$ have reported that all Speedy/ Ringo proteins share a highly conserved approximately 133-amino acid domain, which has been termed the Speedy/Ringo box and is essential for Cdk binding. Its $51 \%-67 \%$ of region is identical to XRINGO/ Speedy, spans 79 residues. ${ }^{5}$ We investigated the function of LM23 with microarray, Western blot and immunohistochemistry using LM23 gene knockdown rats. As there was increased apoptosis of spermatocytes in the LM23 gene knockdown testis, the activation of caspase 3 was studied using an anti-activated caspase 3 antibody. Elucidation of the function of LM23 may promote insight into mammalian spermatogenesis.

\section{MATERIALS AND METHODS}

Animals

SPF female New Zealand white rabbits (8 weeks old) were purchased from the Animal Center of The National Institute for

${ }^{1}$ Graduate School of the Peking Union Medical College, Beijing 100005, China; ${ }^{2}$ Department of Reproductive Endocrinology, National Research Institute for Family Planning, Beijing 100081, China and ${ }^{3}$ Air Force Institute of Aviation Medicine, Beijing 100142, China Correspondence: Professor MC Jia (jmchun48@yahoo.com.cn)

Received: 11 December 2010; Revised: 17 January 2011; Accepted: 28 February 2011 
Control of Pharmaceutical and Biological Products (Beijing, China). LM23 gene knockdown male $R$. norvegicus SpragueDawley rats (5 weeks old) were obtained from our animal facility. ${ }^{2}$ Animals were maintained under controlled temperature $\left(25{ }^{\circ} \mathrm{C}\right)$ and lighting ( $14 \mathrm{~h}$ light and $10 \mathrm{~h}$ dark) and were allowed free access to food and water. All experiments were conducted according to the guidelines of the Chinese Animal Care for Laboratory Animals, and the protocols were approved by the Animal Care and Use Committee in the National Research Institute for Family Planning (Beijing, China).

\section{BLAST}

Alignments of the conserved Speedy/Ringo boxes of mouse Speedy/ Ringo A (79 residues) and LM23 were performed using the BLAST tool (http://blast.ncbi.nlm.nih.gov/Blast.cgi? $\mathrm{CMD}=$ Web\&PAGE_TYPE = BlastHome).

\section{Structural domains and functional motifs of LM23}

We used ScanProsite (Swiss Institute of Bioinformatics, Lausanne, Switzerland) at the EXPASY to identify PROSITE motifs in the LM23 protein. ScanProsite consists of documentation entries describing protein domains, families and functional sites, as well as associated patterns and profiles to identify these features. ${ }^{6}$ The amino-acid sequence of LM23 in single-letter format was submitted to the ScanProsite server (http://www.expasy.org/prosite/).

\section{Production of a polyclonal rabbit anti-LM23 antibody}

A rabbit polyclonal antibody against the $\mathrm{NH}_{2}$-terminal and $\mathrm{COOH}$ terminal peptides of the LM23 protein was generated. According to the DNAStar soft, ${ }^{7}$ analysis and prediction of the possible structure, hydrophilicity and antigenicity of LM23, two peptides (amino acids 1-20 and 274-291) of LM23 were synthesized using standard Fmocbased Synthesis of Peptide Protocol. The synthesized peptides were purified by reversed phase high-performance liquid chromatography and crosslinked with keyhole limpet hemocyanin by 1-ethyl-3(3-dimethylaminopropyl) carbodiimide. ${ }^{8}$ Rabbits were immunized three times ( $100 \mu \mathrm{g} / \mathrm{rabbit})$ with the conjugated peptides. The sensitivity and specificity of the LM23-keyhole limpet hemocyaningenerated rabbit polyclonal antibody were evaluated by ELISA and Western blot.

\section{Cloning of the $L M 23$ gene from rat testis and expression of the LM23 protein in Escherichia coli}

LM23 RNA was extracted from rat testis tissue and amplified by RTPCR. After purification and recovery, the cDNA fragment of LM23 was cloned into a TA vector. The fragment was then sequenced, subcloned into the plasmid pET28a $(+)$ (Novagen, Darmstadt, Germany), expressed in E. coli BL21, and identified by SDS-PAGE and Western blot analysis (anti-LM23, rabbit polyclonal peptide antibody, generated by our lab).

Microarray analysis to identify LM23-regulated genes in testis To identify potential target genes that may be regulated by LM23, microarray analysis (service provided by Kangchen Biotech, Shanghai, China) was performed to survey the gene expression of LM23-shRNA testis and controls using Agilent rat whole genome arrays (design ID 14879).

\section{Immunohistochemical analysis}

Testis were fixed in Bouins solution, dehydrated and embedded in paraffin using standard methods. Immunostaining was performed using a commercial immunohistochemistry kit (Zhongshan Bio Co., Beijing, China) according to the suggested protocol of the manufacturer. Paraffin tissue sections ( $5 \mu \mathrm{m}$ thick) were placed on the poly-L-lysine-coated slides and deparaffinized. To suppress endogenous peroxidase activity, the tissue sections were then treated with $3 \% \mathrm{H}_{2} \mathrm{O}_{2}$ in methanol for $10 \mathrm{~min}$. Antigen retrieval was performed by heating the sections in $10 \mathrm{mmol}^{-1}$ citric acid solution ( $\mathrm{pH}$ 6.0) using an autoclave. The immunoreaction was detected by the streptavidin-horseradish peroxidase method. The primary antibodies (Ab) were as follows: anti-LM23 (rabbit, polyclonal peptide $\mathrm{Ab}$; our lab), anti-Cdk2 (mouse, monoclonal Ab, MAB-390; Lab vision Co., CA, USA), anti-Cyclin A1 (rabbit, polyclonal peptide Ab, RB-1548-P1ABX; Thermo Fisher Scientific Inc., New York, USA) and anti-caspase 3 (mouse, monoclonal Ab, BA0588; Boshide Co., Wuhan, China). The optimal working dilution of each antibody was determined by incubating the sections with various concentrations of antibody. A final color reaction was performed using liquid 3,3'-diaminobenzidine tetrahydrochloride. The slides were then mounted with Canada balsam. The negative control was processed with non-immune serum instead of the polyclonal antibody. Each experiment was repeated at least three times, and similar results were obtained.

\section{RESULTS}

\section{BLAST}

LM23 was 97\% identical to the Speedy/Ringo box of mouse Speedy/ Ringo A, which is essential for Cdk binding (Figure 1).

Predicted functional motifs of LM23 protein by ScanProsite server We used the ScanProsite server at the EXPASY (http://ca.expasy. org/tools/scanprosite/) to identify PROSITE motifs in the LM23 protein. PROSITE predicts that LM23 contains two $\mathrm{N}$-glycosylation sites, seven protein kinase $\mathrm{C}$ phosphorylation sites, five casein

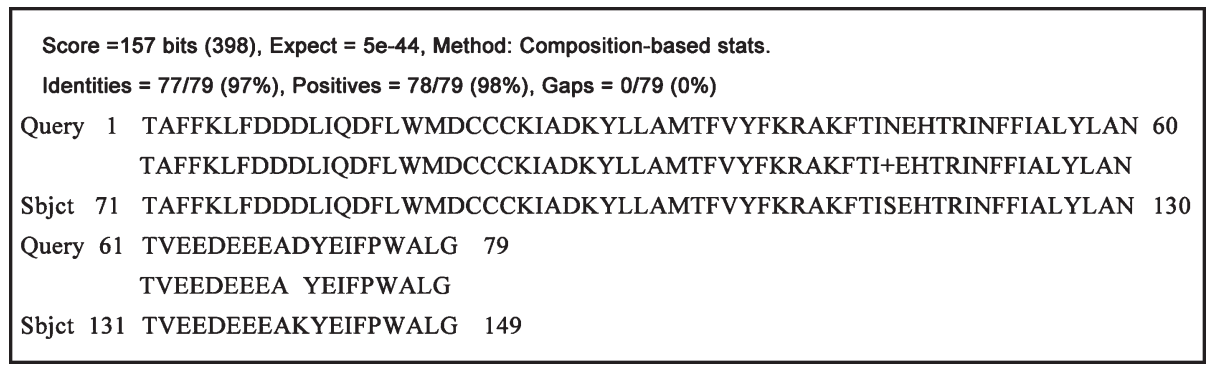

Figure 1 The results of the BLAST search of LM23. 
kinase II phosphorylation sites, three $N$-myristylation sites and two amidation sites. These motifs suggest that LM23 may be subjected to modifications in the cell, which may be critical for its potential functions (Table 1).

\section{LM23 polyclonal antibody production}

Two synthesized peptides with a purity of $90 \%$ were prepared. The titers of the purified polyclonal antibodies were 1:64000 and 1:128 000 detected by ELISA. The Western blot analysis showed that the antibody (amino acids 274-291) detected an immunoreactive protein with a molecular weight of $36 \mathrm{kDa}$ in the total nucleoprotein of rat testis (Figure 2). The predicted molecular weight of the LM23 protein is $36 \mathrm{kDa}$.

Table 1 Analysis of the domain structure of LM23 using the ScanProsite server

\begin{tabular}{lcl}
\hline Site & Position & Domain \\
\hline N-glycosylation site & 23 & NRSH \\
Protein kinase C phosphorylation site & 293 & NETN \\
& 22 & SNR \\
& 28 & TRK \\
& 33 & SLK \\
& 46 & SEK \\
Casein kinase II phosphorylation site & 177 & SRR \\
& 255 & TGK \\
& 289 & SKK \\
& 113 & TISE \\
-myristoylation site & 131 & TVEE \\
& 223 & TPVD \\
Amidation site & 247 & SSSD \\
& 289 & SKKE \\
& 21 & GSNRSH \\
& 204 & GAARNY \\
& 240 & GLSSSS \\
& 230 & CGKK \\
& 255 & TGKR \\
\hline
\end{tabular}

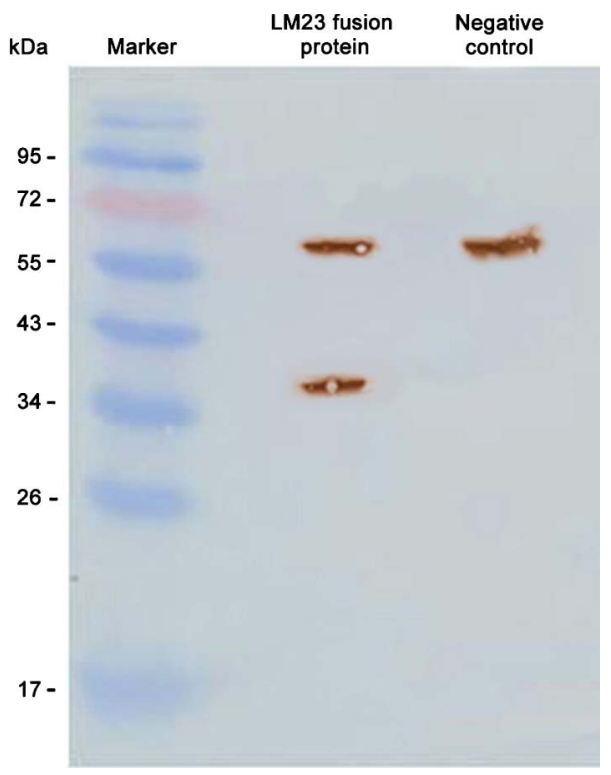

Figure 2 Western blot analysis of LM23 protein expression in testis of SD rat (DAB). Negative control, normal rabbit serum. DAB, 3,3'-diaminobenzidine tetrahydrochloride.
Cloning of the LM23 gene from rat testis and expression of the LM23 protein in $E$. coli

A DNA fragment of approximately $900 \mathrm{bp}$ was amplified. The sequencing result showed that this fragment contained only rat LM23 cDNA (939 bp, Open Reading Frame). This LM23 cDNA was subcloned into pET28a $(+)$, and the recombinant $36-\mathrm{kDa} \mathrm{LM} 23$ protein was induced by IPTG. The LM23 fusion protein expressed by E. coli was analyzed by SDS-PAGE and Western blotting. The results of SDS-PAGE showed that the molecular weight of the fusion protein was $36 \mathrm{kDa}$ and that the fusion protein was expressed in an inclusion body (Figure 3a). The Western blot analysis showed that the LM23 antibodies detected an immunoreactive protein with a molecular weight of $36 \mathrm{kDa}$ in the E. coli expressing the LM23 fusion protein (Figure $3 \mathbf{b}$ ).

\section{Subcellular localization of LM23 by immunohistochemistry}

To examine cell-specific expression in rat testis, a polyclonal rabbit anti-LM23 antibody was used for immunohistochemical detection.

a

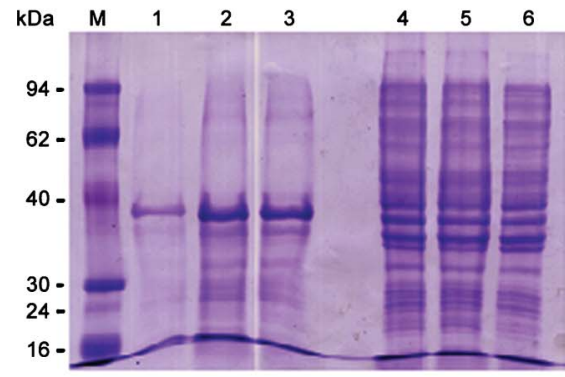

b

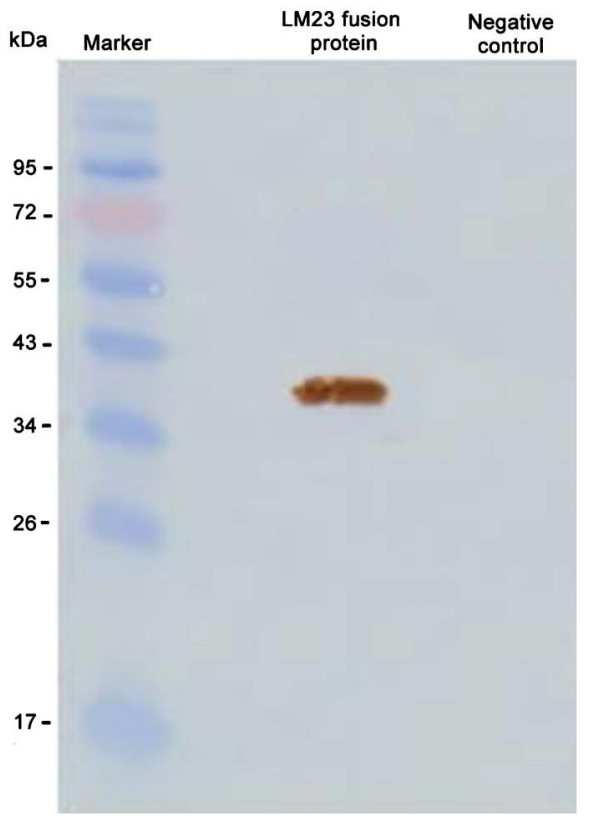

Figure 3 Analysis of the E. coli expressing the LM23 fusion protein by SDSPAGE (a). Analysis of the E. coli expressing the LM23 fusion protein by Western blotting with the LM23 polyclonal antibody (b). Lane 1, inclusion body after induction by IPTG for $2 \mathrm{~h}$; Lane 2, inclusion body after induction by IPTG for $4 \mathrm{~h}$; Lane 3 , inclusion body after induction by IPTG for $6 \mathrm{~h}$; Lane 4 , soluble protein after induction by IPTG for $2 \mathrm{~h}$; Lane 5 , soluble protein after induction by IPTG for $4 \mathrm{~h}$; Lane 6 , soluble protein after induction by IPTG for $6 \mathrm{~h}$. Negative control, E. coli. M, marker. 
Positive immunoreactivity was mainly located in spermatocytes. The subcellular localization of LM23 was primarily in the nucleus (Figure 4).

\section{Microarray analysis and immunohistochemistry of a rat model of LM23 gene knockdown}

LM23 knockdown testis tissue and control tissue from $R$. norvegicus were used for histological analyses at 4 weeks post-transfection. The seminiferous tubule of the control testis contained a full spectrum of germ cells: spermatogonia, pachytene spermatocytes, round spermatids and elongated spermatids (Figure 5b). In contrast, the seminiferous tubules of LM23 knockdown testis appeared disorganized, disrupted and were shedding germ cells into the lumina (Figure 5a). The germ cells exhibited complete meiotic arrest in spermatogenesis. Spermatocytes were accumulated, round spermatids were few, and elongating spermatids and spermatozoa were absent in certain LM23 knockdown seminiferous tubules (Figure 5a). Three major types of seminiferous tubules were observed in LM23 knockdown testis. Type A tubules contained many layers of spermatocytes and many heavily eosin-stained cells. Type B tubules contained 3-4 layers

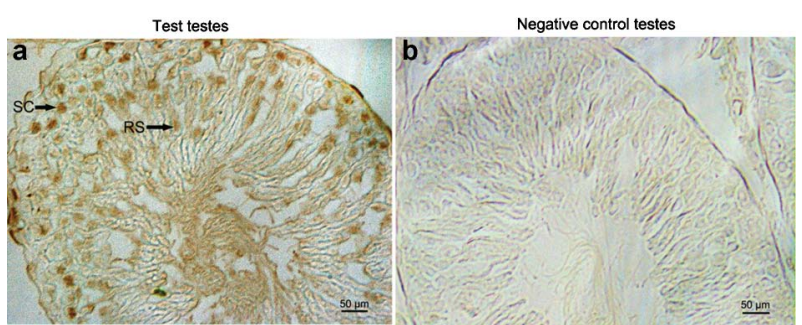

Figure 4 Immunohistochemical analysis of LM23 protein expression in testis of Sprague-Dawley rat. The positive immunological activity was mainly located in the nucleus of spermatocytes (SC) and round spermatids (RS), but few in elongating spermatids and mature sperm. of spermatocytes. Type $\mathrm{C}$ tubules were characterized by a few layers of spermatogenic cells/Sertoli cells and large empty lumina.

The expression of some genes related to the cell cycle and apoptosis was markedly changed after LM23 knockdown, as shown by the microarray analysis (Tables 2 and 3). The downregulation of LM23 might block the $\mathrm{G}_{1} / \mathrm{S}$ and $\mathrm{G}_{2} / \mathrm{M}$ transitions of the spermatogenic cell (Figure 6). The downregulated LM23 may active both the Fas-FasL pathway and the mitochondrial pathway during spermatogenesis.

Some cell cycle genes (Cdk2, CyclinA1 and Caspase 3) were chosen for further analysis. Immunohistochemical analysis confirmed that expression of all of these proteins was markedly altered in LM23 knockdown testis compared to the controls (Figure 7).

\section{DISCUSSION}

To visualize the subcellular localization of the LM23 protein, a rabbit polyclonal antibody against LM23 was generated. The LM23 polyclonal antibody can detect an immunoreactive protein with a molecular weight of $36 \mathrm{kDa}$ in the total nucleoprotein of rat testis using Western blot analysis (Figure 2). The 60-kDa band may be a nonspecific band. However, the LM23 antibody also detected an immunoreactive protein with molecular weight of $36 \mathrm{kDa}$ in the E. coli expressing the

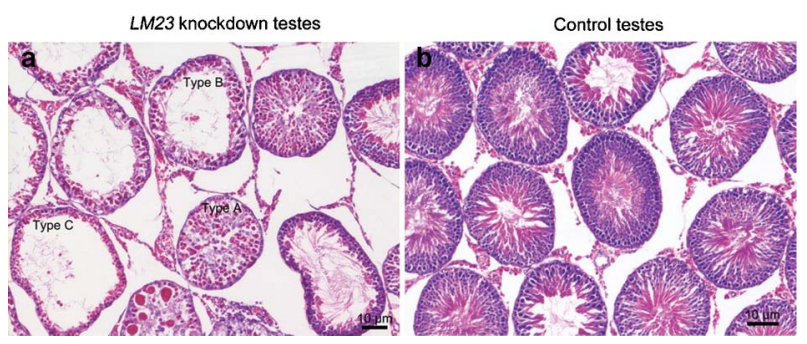

Figure 5 The seminiferous tubules, stained with hematoxylin and eosin, of $L M 23$ knockdown and the control testes in $R$. norvegicus at 4 weeks post-transfection.

Table 2 List of genes associated with cell cycle expression after LM23 knockdown

\begin{tabular}{|c|c|c|c|c|}
\hline Gene symbol & Test/control & Array ID & ID number & Description \\
\hline Cdk4 & 3.369 & A_44_P388782 & NM_053593 & Cyclin-dependent kinase 4 \\
\hline Cdk6 & 0.231 & A_44_P405071 & XM_342638 & Cyclin-dependent kinase 6 \\
\hline Ccnd 1 & 13.05 & A_44_P189299 & NM_171992 & Cyclin D1 \\
\hline Ccnd2 & 6.244 & A_44_P477768 & NM_022267 & Cyclin D2 \\
\hline Ccnd3 & 10 & A_43_P15524 & NM_012766 & Cyclin D3 \\
\hline$C d k n 2 b(p 15)$ & 0.068 & A_44_P313507 & NM_130812 & Cyclin-dependent kinase inhibitor 2B ( $p 15$, inhibits Cdk4) \\
\hline Cdkn2a (p16) & 24.3 & A_44_P395885 & NM_031550 & Cyclin-dependent kinase inhibitor $2 \mathrm{~A}$ \\
\hline$C d k n 2 d(p 19)$ & 3.545 & A_44_P444257 & NM_001009719 & Similar to cyclin-dependent kinase inhibitor 2D \\
\hline$C d k n 1 a(p 21)$ & 2.394 & A_44_P515275 & NM_080782 & Cyclin-dependent kinase inhibitor $1 \mathrm{~A}$ \\
\hline$C d k n 1 b(p 27)$ & 7.089 & A_44_P508264 & NM_031762 & Cyclin-dependent kinase inhibitor 1B \\
\hline$R b 1$ & 3.268 & A_44_P229079 & D25233 & Retinoblastoma 1 \\
\hline$R b / 2$ & 4.108 & A_43_P15508 & NM_031094 & Retinoblastoma-like 2 \\
\hline$E 2 F 1$ & 3.042 & A_44_P349002 & XM_230765 & E2F transcription factor 1 \\
\hline Cdk2 & 0.441 & A_42_P785419 & NM_199501 & Cyclin-dependent kinase 2 \\
\hline Ccnal & 0.0234 & A_44_P995716 & NM_001011949 & Cyclin A1 \\
\hline Ccne2 & 0.341 & A_44_P272210 & XM_342804 & Cyclin E2 \\
\hline Ccnb1 & 0.177 & A_44_P534089 & NM_171991 & Cyclin B1 \\
\hline Ccnb2 & 0.309 & A_44_P461544 & NM_001009470 & Cyclin B2 \\
\hline Ccnb3 & 0.0945 & A_44_P422082 & XM_228779 & Cyclin B3 \\
\hline$A p c$ & 3.349 & A_44_P276106 & NM_012499 & $\begin{array}{l}\text { Adenomatosis polyposis coli, negative regulation of cyclin- } \\
\text { dependent protein kinase activity }\end{array}$ \\
\hline Cdc $25 c$ & 0.465 & A_44_P140314 & XM_226071 & Cell division cycle 25 homolog $\mathrm{C}$ \\
\hline Mdm2 & 0.14 & A_43_P16885 & XM_235169 & Transformed mouse 3T3 cell double minute 2 homolog \\
\hline
\end{tabular}


Table 3 List of genes associated with apoptosis with altered expression after $L M 23$ knockdown

\begin{tabular}{lclll}
\hline Gene symbol & Test/control & Array ID & ID number & \multicolumn{1}{c}{ Description } \\
\hline Casp1 & 14.25 & A_44_P468258 & NM_012762 & Caspase 1, induction of apoptosis \\
Casp2 & 2.411 & A_44_P1019923 & NM_022522 & Caspase 2, induction of apoptosis \\
Casp3 & 63.61 & A_44_P530813 & NM_012922 & Caspase 3, apoptosis-related cysteine protease \\
Casp4 & 14.13 & A_44_P1028549 & NM_053736 & Caspase 4, apoptosis-related cysteine peptidase, induction of apoptosis \\
Casp6 & 17.11 & A_44_P540910 & NM_031775 & Caspase 6, induction of apoptosis \\
Casp7 & 7.611 & A_44_P183488 & NM_022260 & Caspase 7, induction of apoptosis \\
Casp8 & 34.47 & A_44_P298210 & NM_022277 & Caspase 8, caspase activity \\
Myc & 23.36 & A_42_P493380 & NM_012603 & Myelocytomatosis viral oncogene homolog \\
p53 & 5.626 & A_44_P118929 & NM_030989 & Tumor protein p53 \\
Bid & 52.64 & A_44_P550497 & NM_022684 & BH3 interacting domain death agonist, positive regulation of apoptosis \\
Bax & 10.66 & A_43_P11800 & NM_017059 & Bcl2-associated X protein, induction of apoptosis \\
Apaf1 & 14.56 & A_43_P12379 & NM_023979 & Apoptotic peptidase activating factor 1 \\
Cycs & 4.021 & A_44_P851810 & NM_012839 & Cytochrome C \\
Faslg & 4.408 & A_44_P409820 & NM_012908 & Fas ligand (TNF superfamily, member 6) \\
Fadd & 14.39 & A_44_P258773 & NM_152937 & Fas (TNFRSF6)-associated via death domain \\
\hline
\end{tabular}

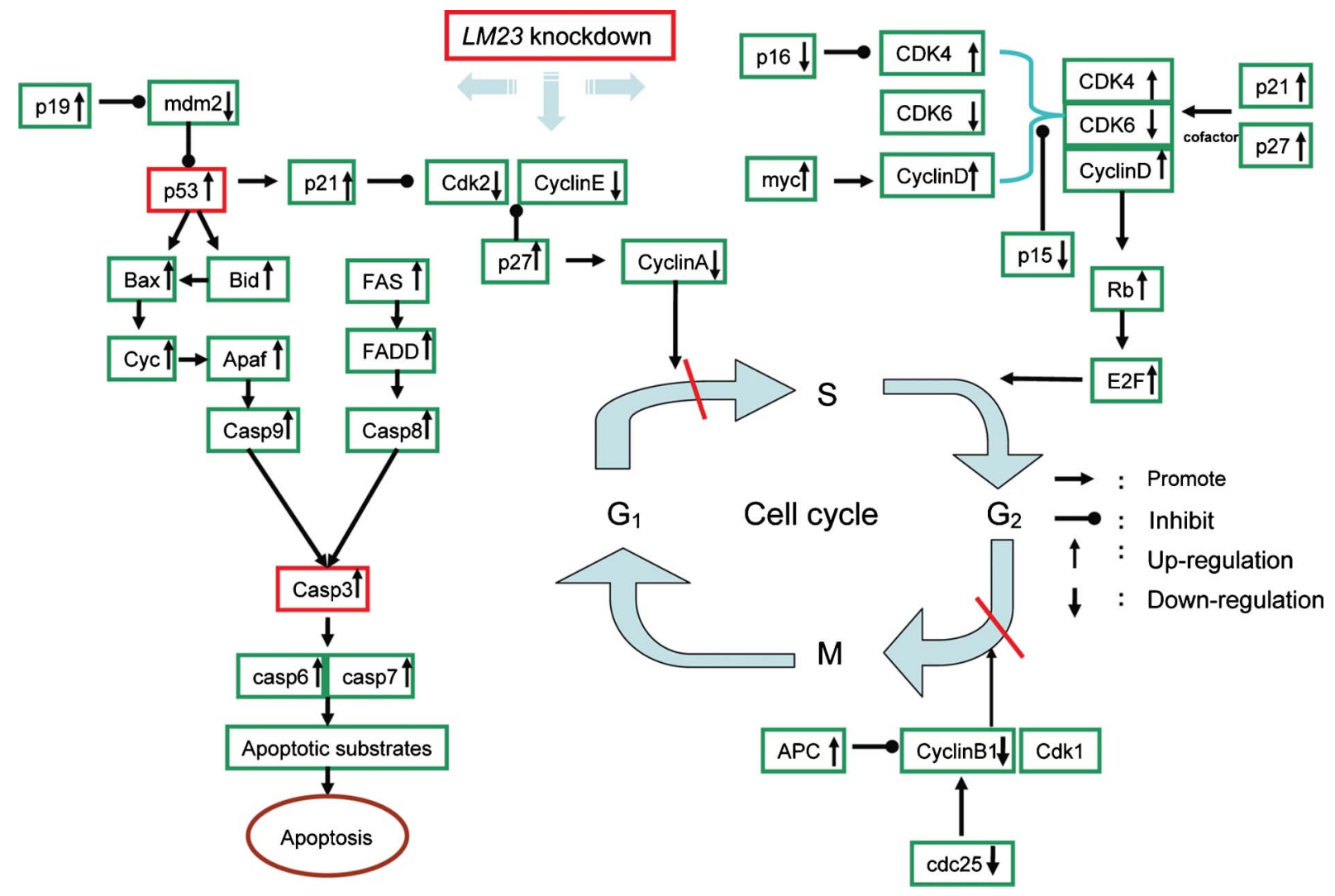

Figure 6 The expression of some genes related to the cell cycle and apoptosis were significantly changed after LM23 knockdown, as shown by microarray analysis. The downregulation of $L M 23$ may block the $G_{1} / S$ and $G_{2} / M$ phase transitions of the spermatogenic cell. Both the Fas-Fas $L$ pathway and the mitochondrial pathway may be activated upon the downregulation of $L M 23$ during spermatogenesis.

LM23 fusion protein (Figure 3). These results further confirmed the reliability of the LM23 polyclonal antibodies and the LM23 fusion protein. Immunohistochemical analysis demonstrated that the positive immunoreactivity was mainly located in the nucleus of spermatocytes and round spermatids (Figure 4). These results indicated that LM23 is localized to the nucleus. The testis-specific and stage-specific expression characteristics of LM23 suggested that LM23 might be involved in $R$. norvegicus spermatogenesis. Therefore, the activation of LM23 is likely to promote meiosis in the spermatogenic cell.
LM23 is 97\% identical to the Speedy/Ringo box of mouse Speedy/ Ringo A. The EST database reveals that LM23 is a R. norvegicus homo$\log$ of RINGO/Speedy A. Speedy A can activate Cdks that can regulate cell cycle progression. ${ }^{4}$ The results from our immunohistochemical analysis showed that LM23 and Cdk2 were both located in the nucleus of spermatocytes and round spermatids (Figures 4 and 7). LM23 may also play a role the cell cycle regulation.

A rat LM23-deficient model reveals a significant role for LM23 in rat spermatogenesis. The germ cells of the LM 23 knockdown testis 


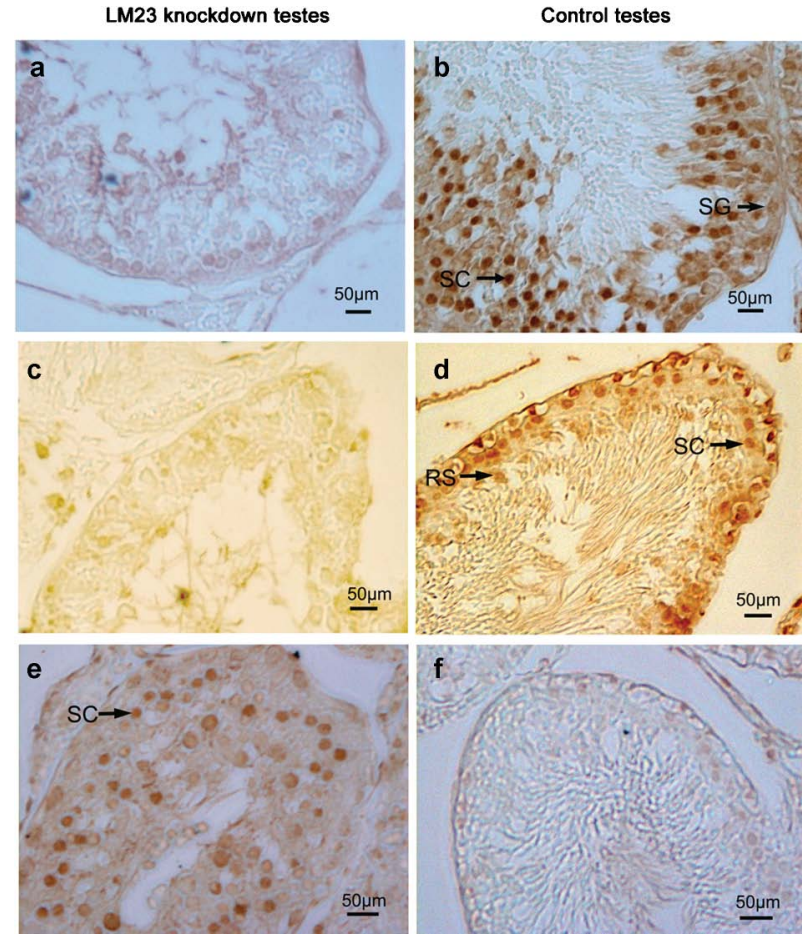

Figure 7 Immunohistochemical analysis with a cyclin Al antibody. The positive immunoreactivity was mainly located in the nucleus of spermatogonia (SG) and spermatocytes (SC) in wild-type rat (b), but few in the LM23 knockdown rat (a). Immunohistochemical analysis with a Cdk2 antibody. The positive immunoreactivity was mainly located in the nucleus of $\mathrm{SC}$ and round spermatids (RS) in wild-type rat (d), but few in the LM23 knockdown rat (c). Immunohistochemical localization of activated caspase 3 in adult testis sections of wild-type rat (f) and the $L M 23$ gene knockdown rat (e). Activated caspase 3 subunit is detected only in the SC of the LM23 gene knockdown testis sections, in the nucleus, as well as the cytoplasm.

exhibited a complete meiotic arrest in spermatogenesis. These results reveal that LM23 expression in the testis is crucial for meiosis during spermatogenesis in $R$. norvegicus. Although a number of genes are known to be involved in spermatogenesis, only a few possess clean-cut arrest phenotypes, indicative of their role in the global regulation of key spermatogenic steps. LM23 gene knockdown rats have a meiotic phenotype that is similar to $\mathrm{Cdk} 2^{-/-}$ and $\mathrm{Cyclin} \mathrm{A}^{-1-}$ mice, including germ cell arrest at the spermatocyte stage. Cdk2 $2^{-/-}$seminiferous tubules are smaller than the wild type and show defective germ cell development. Post-meiotic cells (late spermatocytes, spermatids and spermatozoa) are absent. ${ }^{9}$ Cyclin A1 is a partner of Cdk2. In Cyclin $\mathrm{Al}^{-/-}$mice, male germ cells of the testis cannot enter the first meiotic division. ${ }^{10}$ The similarity in phenotypes of these models suggests that all of these proteins seem to be involved in a mechanism at the meiosis I-meiosis II transition in spermatogenesis.

Microarray analyses of the transcriptomes of the LM23-shRNA and control testes were performed to screen for the genes regulated by LM23. The results revealed that the expression of many genes associated with the cell cycle and apoptosis was markedly altered after LM23 knockdown (Tables 2 and 3). Immunohistochemical analysis further confirmed that $C y c l i n A 1$ and $C d k 2$, which are very important in the cell cycle, displayed lower expression after LM23 knockdown (Figure 7). The LM23 gene knockdown testis showed significantly increased apoptotic cells compared to the control group. ${ }^{3}$ Because most apoptotic signalling pathways culminate in the activation of caspase 3 , enhanced caspase 3 activation was also found in the LM23 gene knockdown testis by immunohistochemical analysis (Figure 7e and f). In our experiment, the expression of $M y c$, Cyclin D, Cdk4, Rb, p21, p27 and E2F increased after LM23 knockdown (Table 2 and Figure 6). Moreover, the expression of p15 and p16 decreased after LM23 knockdown (Table 2 and Figure 6). Therefore, the downregulation of LM23 cannot block the progression of the spermatogenic cell into $S$ phase. ${ }^{11-14}$. Our study showed that the levels of $m d m 2, C d k 2, C y c l i n E$ and CyclinA significantly decreased, but the levels of $p 19, p 53, p 21$ and $p 27$ increased after LM23 knockdown (Table 2 and Figure 6). Therefore, the downregulation of LM23 may prevent the spermatogenic cell from entering $S$ phase. ${ }^{15-21}$ In our study, the expression of APC was increased after LM 23 knockdown (Table 2 and Figure 6). In addition, the expression of CyclinB1 and $c d c 25$ decreased after LM23 knockdown. Therefore, the downregulation of LM23 may prevent the spermatogenic cell from entering $M$ phase. ${ }^{22}$ Our study showed that the levels of $p 53$, Bax, BID, Cytochrome C, Apaf-1, caspase 9, caspase 3, caspase 6 and caspase 7 significantly increased after LM23 knockdown (Table 3 and Figure 6). Therefore, the activation of caspase 3 was likely to be mediated by the mitochondrial pathway after LM23 knockdown. ${ }^{23-30}$ In our study, increased expression of Fas, FADD, caspase 8, cytochrome c, caspase 3, caspase 6 and caspase 7 was observed after LM23 knockdown (Table 3 and Figure 6). Therefore, the activation of caspase 3 was also likely to be mediated by the Fas-FasL pathway after LM23 knockdown. ${ }^{31-35}$

In conclusion, this study has shown that the knockdown of LM23 could result in the downregulation of Cyclin A1, Cdk2 and CyclinB1 and a delay in the progression to $S$ phase and $G_{2}$ phase and eventually leads to cell apoptosis. These results suggest that LM23 belongs to the Speedy/Ringo family and that $L M 23$ regulates the $G_{1} / S$ and $G_{2} / M$ transitions of the cell cycle during spermatogenesis. Both the Fas-FasL pathway and the mitochondrial pathway may be activated by the downregulation of $L M 23$ gene during spermatogenesis. Future studies will further elucidate the function of $L M 23$ and provide insight into its physiological role.

\section{AUTHOR CONTRIBUTIONS}

MCJ conceived the original idea, designed the study, provided professional advice and edited the manuscript. YMC carried out all the experiments and prepared the original manuscript. MLL designed and carried out the experiments in Figure 6, Table 2 and Table 3.

\section{COMPETING FINANCIAL INTERESTS}

The authors declare no competing financial interests.

\section{ACKNOWLEDGMENTS}

The authors thank Xin-Quan Shi, De-Yu Liu, Da-Guang Sun, Hong-Fei Xia, Qian-Xin Wang, Chong Wang, Dan Li, Xiang-Bo Xu, Yong-Jie Chang and Nan Yao for technical assistance. This work was supported by the National Natural Science Foundation of China (No. 30670784).

1 Zirkin BR. Regulation of spermatogenesis in the adult mammal: gonadotrophin and androgens. In: Desjardins CD, Ewing LL, editors. Cell and Molecular Biology of the Testis. New York: Oxford University Press; 1993. pp166-88.

2 Liu ML, Pei KY, Shi XQ, Liu DY, Jia MC. Identification and characterization of a novel spermatogenesis related gene $L M 23$ in rat testis. Biochem Biophys Res Commun 2007; 356: 576-81.

3 Liu ML, Cheng YM, Jia MC. LM23 is essential for spermatogenesis in Rattus norvegicus. Front Biosci 2010; 2: 187-94. 
LM23 is a novel member of the Speedy/Ringo family

YM Ching et al

452

4

Ching A, Xiong W, Ferrell JE Jr, Solomon MJ. Identification and comparative analysis of multiple mammalian Speedy/Ringo proteins. Cell Cycle 2005; 4: 155-65.

5 Ana D, Laurent HP, Amparo D, Markus S, Tim H et al. Characterization of a new family of cyclin-dependent kinase activators. Biochem J 2005; 386: 349-55.

6 Danishuddin, Khan AU. Analysis of PB2 protein from H9N2 and H5N1 avian flu virus. Bioinformation 2008; 3: 41-6.

7 Kong L, Li Y, Yang Y, Li K. Expression of fusion IL2-B7.1 (IV + C) and effects on T lymphocytes. Biochem Cell Biol 2007; 85: 685-95.

8 Naz RK. Immunocontraceptive effect of Izumo and enhancement by combination vaccination. Mol Reprod Lev 2008; 75: 336-44.

9 Berthet C, Aleem E, Coppola V, Tessarollo L, Kaldis P. Cdk2 knockout mice are viable. Cur Biol 2003; 13: 1775-85.

10 Liu D, Matzuk MM, Sung WK, Gro Q, Wang P et al. Cyclin A1 is required for meiosis in the male mouse. Nat Genet 1998; 20: 377-80.

11 Blagosklonny MV, Pardee AB. The restriction point of the cell cycle. Cell Cycle 2002; 1: 103-10.

12 Weintraub SJ, Chow KN, Lu RX, Zhang SH, He S et al. Mechanism of active transcriptional repression by the retinoblastoma protein. Nature 1995; 375: 812-5.

13 Ohtani K. Implication of transcription factor E2F in regulation of DNA replication. Front Biosci 1999; 4: D793-804.

14 Blain SW. Switching cyclin D-Cdk4 kinase activity on and off. Cell Cycle 2008; 7: 892-8.

15 Pagan M, Pepperkok R, Verde F, Ansorge W, Draetta G. Cyclin A is required at two points in the human cell cycle. EMBO J 1992; 11: 961-71.

16 van den Heuvel S, Harlow E. Distinct roles for cyclin-dependent kinase in cell cycle control. Science 1993; 262: 2050-4.

17 Pagano M, Pepperkok R, Lukas J, Baldin V, Ansorge W et al. Regulation of the cell cycle by the cdk2 protein kinase in cultured human fibroblasts. J Cell Bio/ 1993; 121: 101-11.

18 Ohtsubo M, Theodora AM, Schumacher J, Roberts JM, Pagano M. Human cyclin E, a nuclear protein essential for the G1-to-S phase transition. Mol Cell Biol 1995; 15: 2612-24.

19 Kamijo T, Weber JD, Zambetti G, Lindy F, Russel MF et al. Functional and physical interactions of the ARF tumor suppressor with p53 and Mdm2. Proc Natl Accad Sci USA 1998; 95: 8292-7.

20 Gulf GM, Lion YC, Ry A, Lee SW, Lu KP. Role of Pin 1 in the regulation of p53 stability and p21 transactivation, and cell cycle checkpoints in response to DNA damage. J Biol Chem 2002; 277: 47976-9.
21 Gartel AL, Radhakrishnan SK. Lost in transcription: p21 repression, mechanisms, and consequences. Cancer Res 2005; 65: 3980-5.

22 Morgan, David. The Cell Cycle: Principles of Control. London: New Science Press; 2007. pp96-8.

23 Matsui Y, Nagano R, Obinata M. Apoptosis of fetal testicular cells is regulated by both p53-dependent and independent mechanisms. Mol Reprod Dev2000; 55: 399-405.

24 Tim LB, Hermien LR, Iris SG, Paul PW, Gabriel GG et al. The role of the tumor suppressor p53 in spermatogenesis. Cell Death Differ 1998; 5: 669-77.

25 Yin Y, Stahl BC, deWolf WC, Morgentaler A. p53-mediated germ cell quality control in spermatogenesis. Lev Biol 1998; 204: 165-71.

26 Desagher S, Osen-Sand A, Nichols A, Estes R, Montessuit S et al. Bid-induced conformational change of $\mathrm{Bax}$ is responsible for mitochondrial cytochrome $\mathrm{c}$ release during apoptosis. J Cell Biol 1999; 144: 891-901.

27 Thornborrow EC, Manfred JJ. The tumor suppressor protein $\mathrm{p} 53$ requires a cofactor to activate transcriptionally the human BAX promoter. J Biol Chem 2001; 276: 15598 608.

28 Letai A, Bassik MC, Walensky LD, Sorcinelli MD, Weiler S et al. Distinct BH3 domains either sensitize or activate mitochondrial apoptosis, serving as prototype cancer therapeutics. Cancer Cell 2002; 2: 183-92.

29 Kuwana T, Bouchier-Hayes L, Chipuk JE, Bonzon C, Sullivan BA et al. BH3 domains of $\mathrm{BH} 3-o n l y$ proteins differentially regulate Bax-mediated mitochondrial membrane permeabilization both directly and indirectly. Mol Cell 2005; 17: 525-35.

30 Kuwana T, Mackey MR, Perkins G, Ellisman MH, Latterich M et al. Bid, Bax, and lipids cooperate to form supramolecular openings in the outer mitochondrial membrane. Cell 2002; 111: 331-42.

31 Pentikäinen V, Erkkilä K, Dunkel L. Pas regulates germ cell apoptosis in the human testis in vito. Am J Physio 1999; 276: E310-6.

32 Medema JP, Scaffidi C, Kischkel FC, Shevchenko A, Mann M et al. FLICE is activated by association with the CD95 death-inducing signaling complex (DISC).EMBO J1997; 16: 2794-804.

33 Kabra NH, Yang C, Hing LC, Chang J, Winoto A. T cell-specific FADD-deficient mice: FADD is required for early T cell development. Proc Natl Acid Sci USA 2001; 98 : 6307-12.

34 Muzio M, Chinnaiyan AM, Kischkel FC, O'Rourke K, Shevchenko A et al. FLICE, a novel FADD-homologous ICE/CED-3-like protease, is recruited to the CD95 (Frs/ APO-1) death-inducing signaling complex. Cell 1996; 85: 817-27.

35 Boldin MP, Goncharov TM, Goltsev YV, Wallach D. Involvement of MACH, a novel MORT1/FADD-interacting protease, in Fas/APO-1- and TNF receptor-induced cell death. Cell 1996; 85: 803-15.

Asian Journal of Andrology 